\title{
Publishing for a Technical Community
}

\author{
A.W. Kenneth Metzner
}

Publishing has been much in the news recently. Two dominant themes have been the takeovers of publishing companies by media giants and the huge advances paid to brand-name authors. Both are themes of "trade publishing" (fiction and nonfiction sold in bookstores), and neither has much relevance to scholarly and professional publishing in science and technology. Trade publishers, under corporate pressure to improve profit margins (5-10\%), look with envy at the margins in textbook and professional publishing (10-15\%) and only dream of those earned by the canny publishers of research journals (15-25\%).

And that is where we have the number one publishing problem facing any technical research community today: How to keep the rising prices of monographs and journals from overwhelming library budgets. It is a problem that has been escalating inexorably since about 1945.

Recently, physicist Barschall' demonstrated the enormous range of journal prices, with society publishers generally at the low end and commercial publishers ranging all the way out into the prohibitive. And he made a solid contribution toward defining measures and criteria of value. It is urgent for the societies that represent the various technical communities to get together with libraries and their consortia, such as the Association of Research Libraries, to develop legally sound procedures for applying such criteria.

At the research level, the authors who need archival recognition, the library users of journals and monographs, the library advisory committee, the grant seekers perturbed by high indirect cost rates, and the editors, editorial boards, and advisory committees of journals and book series (whether commercial or society) are all essentially one and the same. Talk about "interlocking directorates"! Each research community must face this responsibility itself, in its own enlightened self-interest. It is inadequate, and also unrealistic, to set up commercial publishers as the sole villains, because the decision makers in that world are responding to an entirely different imperative. Take note, however, and emulate, the very sound and cautionary practice of commercial publishers having expert lawyers present at all times.

Another publishing problem, or source of publishing opportunities, is the constantly changing dynamics of research fields and technical communities-the "twigging" phenomenon, the rise and fall of interdisciplinary and mission-oriented areas, and the sudden emergence of methods, philosophies, movements, and even fashions. Strong personalities and brilliant minds are often the key factors in such developments. Some societies manage to be flexible in accommodating these changes, both organizationally and in the design of their publishing programs. In others, success has led to ossification and bureaucratization, so that the innovative group can only split to form a new society or quit to work with an eager commercial publisher. And here is where the entrepreneurial agility of commercial publishers performs a real service by providing real alternatives. (But why give them title and copyrights forever?)

A third area of problems for technical publishing, forever with us, is how to adapt the technology of communication and dissemination to the publishing process itself in order to better satisfy the needs of the technical community involved. The pace of change, starting with the application of computers in the late 1960s, followed by the leap to micros in the 1980s and the fax explosion of 1990 , shows no sign of abating. It is easy to foresee (three to six years) the near universal availability of (1) high-resolution printer-copier-fax combos, (2) microcomputers one or two orders of magnitude more powerful than now, (3) networking at all levels from the office to international, and (4) truly portable phonecomputers.
When inspiration strikes, on that backpack trip high in the Sierras, you will be able to use your six-ounce portable to check the latest issue of Journal of Materials Research, run a quick sample calculation of your inspiration, tell a professor friend in Tokyo about it, order a selection of relevant journal articles on your home office printer, and, incidentally, before resuming your hike, verify your precise bearings and altitude. When you get back, publication quality reprints of the articles you ordered will be in your printer's output tray. Yesalthough your monitor-TV will be capable of 1,000 dpi resolution-you will still prefer paper. (There will never be a paperless office.) In general, personal subscriptions will be selective and delivered directly by fax. (The "electronic journal" will find a niche in the much more distant future.)

To take advantage of this developing technology, some hard work on software and standards will be necessary with the participation of the technological community at large, for example on the Standand for Electronic Manuscript Preparation and Markup of the Electronic Publishing Special Interest Group (EPSIG). A journal publisher might also want to develop portfolios of style sheets, one for each of the major word-processing or desktop-publishing packages that the authors might be using, to ensure the delivery of both standard compuscripts and standard camera-ready pages. Standards will also be needed for searchable mass storage media like CDROM.

A more immediate problem in technical publishing on the international level is how to monitor foreign language publications, particularly in Russian and Japanese, and find cost-effective ways to publish translations. This is especially important in technology areas where firstclass applied research published in those languages might be redone in the West because the original work is unknown. Perhaps one of the most urgent tasks is for members of each technical community to talk to their colleagues in these language areas about international information transfer standards and about copublishing ventures of all kinds.

1. H.H. Barschall, Physics Today 41 (7) (1988) p. 56.

Kenneth Metzner is director of ASME Press and editor in chief of Applied Mechanics Reviews. 